\title{
INTERAÇÕES SOCIAIS PRECOCES: UMAANÁLISE DAS MUDANÇAS NAS FUNÇÕES PARENTAIS
}

\section{EARLY SOCIAL INTERACTIONS: AN ANALYSIS OF CHANGES IN THE PARENTAL ROLE}

\author{
Sandra A N Nunes* \\ Marcos G Fernandes** \\ Mauro L Vieira ${ }^{* * *}$
}

Nunes SAN, Fernandes MG, Vieira ML. Interações sociais precoses: uma análise das mudanças nas funções parentais. Rev Bras Crescimento Desenvolv Hum. 2007, 17(3): 160-171.

Resumo: As interações físicas e afetivas estabelecidas entre progenitores e seus descendentes vêm sendo rediscutidas na ciência psicológica, em virtude de contribuições recentes oferecidas pela Psicologia do Desenvolvimento Evolucionista (PDE). Pretende-se, no presente artigo, fazer uma revisão das teorias clássicas e contemporâneas que trataram de explicar os fatores implicados na gênese, no desenvolvimento e na função das interações precoces entre filhos e mães e pais. Buscar-se-á estabelecer as modalidades de vinculação em diferentes espécies, a partir de uma abordagem evolucionista, até se chegar à conduta de apego e à sua contraparte, o comportamento parental, em sua dinâmica normal e patogênica, na espécie homo. A psicopatologia do vínculo mãe-bebê, em especial a depressão puerperal, será analisada tendo como pano de fundo a contradição entre as características biológicas da espécie e as exigências culturais que as sociedades industrializadas impõe à mãe e ao pai, destacando papel que o investimento paterno e aloparental assumem no desenvolvimento favorável do bebê e, conseqüentemente, no reestabelecimento da puérpera

Palavras-chave: Interação social. Apego. Comportamento parental.

\section{INTRODUÇÃO}

As interações sócio-afetivas entre indivíduos e os mecanismos envolvidos na formação do vínculo mãe-bebê, em especial, constituem uma área de interesse compartilhado por diferentes áreas da ciência.

Foi de Charles Darwin" ${ }^{1}$ com a obra "The expression of the emotions in man and animals", o mérito de, originalmente, desvendar as raízes comuns das expressões emocionais de algumas espécies animais e de explicitar as expressões especiais do homem, como o sofrimento e choro ("Special expressions of man: suffering and weeping") e, mais particularmente, de explicar o valor adaptativo do grito e do choro em filhotes ("The screaming and weeping of infants"). Os frutos dessa obra renderam trabalho, durante o século seguinte, para diversas disciplinas científicas que foram se dife-

Professora visitante da Universidade Estadual de Sant Cruz-UESC- BA (Departamento de Ciências da EducaçãoDCIE) e Professora da Faculdade de Tecnologia e Ciências de Itabuna-FTC-BA (Núcleo de Saúde-Curso de Psicologia).

** Professor assistente da Universidade Estadual de Santa Cruz-UESC- BA. Departamento de Ciências da SaúdeDCSAU. Universidade Estadual de Santa Cruz - UESC. Departamento de Ciências da Saúde- DCSAU. Campus Soane Nazaré de Andrade km 16 Rodovia Ilhéus-Itabuna CEP- 45662-000. Ilhéus-Bahia. Tel: (73) 3680-5123/ (73) 9113 7202 -e-mail: gimenes@uesc.br

*** Professor adjunto da Universidade Federal de Santa Catarina-UFSC-SC. Departamento de Filosofia e Ciências Humanas. 
renciando, filosófica e epistemologicamente, no modo como explicaram a gênese, os mecanismos do desenvolvimento e as funções do comportamento de vinculação, tanto em animais como em humanos. Desmembram-se da Psicologia diferentes sub-disciplinas como a Psicologia Social, a Psicologia do Desenvolvimento, a Psicologia da Personalidade, a Etologia e a Psicopatologia.

Independente das áreas de interesse, viuse emergir, nos quase dois séculos de ciência, posturas filosóficas irreconciliáveis que podem ser descritas em termos da clássica disputa entre o inato e o apreendido, o biológico e o social ou, ainda, entre o psíquico e orgânico, que ainda hoje se conservam na base argumentativa das versões mais radicalmente reducionistas de cada uma dessas disciplinas científicas.

Na psicologia científica contemporânea, em suas diferentes áreas: psicologia geral, psicologia do desenvolvimento, psicologia da personalidade, psicologia da aprendizagem, uma postura claramente interacionista orienta as novas investigações para a compreensão dos mecanismos envolvidos na interação entre o equipamento biológico dos indivíduos e as condições contextuais (nutricionais, educativas, afetivas, econômicas etc) em que essa interação ocorre. No caso específico do desenvolvimento infantil, busca-se, atualmente, estabelecer a dinâmica interativa entre as múltiplas capacidades inatas do recém-nascido, desenvolvida ao longo do processo evolutivo e a sensibilidade e responsividade materna e paterna, a contraparte evolutiva da conduta de apego infantil, nos diferentes contextos culturais. A análise realizada é feita com vistas a lançar hipóteses sobre as condições inibidoras ou facilitadoras de uma dinâmica familiar saudável e de um bebê com mais capacidades adaptativas para o mundo atual, diante de um equipamento biológico que o homo sapiens filogeneticamente compartilha com a maioria dos filhotes de mamíferos para construir o apego.

Ao que tudo indica, o homem moderno constrói condições materiais de vida que impõem necessidades inéditas na sua história evolutiva. Necessidades de ordem econômica, política, cultural, estética e tecnológica que criam novas modalidades adaptativas de desenvolvimento psicológico e de interações sociais, inclusive, de dinâmicas familiares. São modos inéditos de agir, de pensar e de sentir que se deparam com um aparato geneticamente programado para viver em condições naturais de subsistência. Dado tamanho embate, ambos, o meio social e as condições orgânicas de nascimento, atuam de forma interativa e transformam-se na ontogênese. Resulta dessa mútua ação interativa um organismo social, cuja indissociação torna-se, virtualmente, impossível com o seu desenvolvimento. Em síntese, a sobrevivência do organismo e da espécie, nos dias atuais, continua condicionada à sua capacidade reprodutiva e adaptativa, entretanto, os mecanismos envolvidos na reprodução e na adaptação da espécie humana tornaram-se complexos, e impõem sua força sobre a base biológica.

A Psicologia do Desenvolvimento Evolucionista (PDE), apoiando-se nos pressupostos darwinistas e a Psicologia Marxista, apoiandose no materialismo histórico e dialético, são exemplos dessa postura interacionista e reconciliadora, pois explicitam as raízes filogenéticas do comportamento do bebê e destacam a interatividade entre o equipamento biológico e o contexto sócio-cultural, como condição necessária para que o desenvolvimento dessas capacidades humanas ocorra.

Dessa forma, busca-se, no presente artigo, articular as contribuições iniciais da Psicologia do Desenvolvimento Clássica e da Etologia moderna às iniciativas da Psicologia Evolucionária e da Psicologia histórico-cultural contemporâneas, para a compreensão das interações mãe-bebê-pai, buscando compreender sua dinâmica normal e patogênica. Além disso, no contexto das patologias da interação mãe-bebê, em especial na depressão puerperal, na qual a mãe exibe baixa responsividade aos sinais de busca de proximidade do bebê, seja por motivos relativos à sua inexperiência, à percepção de falta de suporte social, ou às próprias características inatas do bebê, será discutida a importância que o investimento paterno e aloparental assumem, nas condições culturais e econômicos do mundo ocidental industrializado. 


\section{Os precursores do apego: contribuições da etologia}

Na Europa de meados do século XX, Konrad Zacharias Lorenz (1903-1989) e Niko Tinbergen (1907-1988) deram origem à Etologia moderna, a partir de suas descobertas sobre a organização e a eliciação de padrões de comportamentos sociais e individuais inatos em animais. Foi de Lorenz ${ }^{2}$ o mérito de redescobrir o imprinting ou a estampagem, conceito empregado para definir o comportamento de filhotes de gansos exibidos como resultado da experiência precoce em fixar-se à imagem da primeira figura (geralmente a materna) com que entravam em contato, após eclodir dos ovos, e a tendência em manterem a proximidade com essa figura durante o seu estágio inicial de desenvolvimento.

Para Leontiev ${ }^{3}$ diferentes espécies foram filogeneticamnete programadas para, ao nascer, apresentarem uma capacidade peculiar de eliciar respostas específicas de aproximação das progenitoras. Para esse mesmo autor, nas aves, o equipamento de mútua comunicação biologicamente programado entre filhotes e aves-mães, resultou menos flexível, se comparado aos equipamento dos mamíferos:

"Se apanharmos um pintinho e o retivermos à força, este debate-se e pia: o seu pio atrai a mãe que se precipita na direção desse som e responde com um cacarejar particular." E prossegue: "Encerrando o pintinho preso, sempre piando, numa campânula de vidro grosso que isole o som; a galinha que vê muito bem o seu pintinho, mas não ouve seus gritos não manifesta a menor atividade em relação a ele; a vista do pinto debatendose deixa-a indiferente".

Leontiev $^{3}$ quis demonstrar que os padrões inatos de interação mãe-filhote de aves são de base puramente biológica e parecem pouco adaptativos diante de perturbadores artificialmente impostos. Apenas o sinal sonoro tem função de sobrevivência para esses filhotes, já que podem ser prontamente identificado pela mãe, desper- tando nela um comportamento de proximidade imediata e proteção. Qualquer outro sinal emitido, como é o caso de movimentos desordenados, decorrentes do arousal dos filhotes, não são captados pela mãe como sinal de estresse ou de risco de morte eminente.

E porque razão, nessa espécie, um evidente sinal de "desespero ou medo não teria responsividade materna? De fato, esses mesmos sinais emitidos por filhotes chamariam a atenção de predadores. Do ponto de vista evolutivo, esse fato poderia explicar a decisão biologicamente programada para que a mãe-ave, que precisará fornecer os cuidados necessários para o resto da ninhada, não responda aos sinais de distress acentuado de um único filhote. Esse sinal, demasiadamente intenso, indicaria um risco de morte para a própria mãe e, conseqüentemente, a todos os seus descendentes. Sinais menos intensos como o piado, audível a curta distância, foram fixados, na espécie, em consonância com o comportamento de proteção materna ${ }^{4}$.

Parece oportuno lembrar que os padrões inatos de comportamentos em filhotes estão sendo revistos na psicologia do desenvolvimento contemporânea. Segundo Vieira e Prado ${ }^{5}$, o que é selecionado ao longo do processo de evolução filogenética não é o comportamento propriamente dito mas, sim, certas predisposições para agir. A atualização dessa predisposição, na ontogênese, está condicionada ao contexto ambiental (físico e social) no qual o filhote se desenvolverá. Os autores explicam que, mesmo comportamento reflexos, antes entendidos como não passiveis de reprogramação ambiental, como é o caso do imprinting (ou estampagem), podem ser modulados por experiências individuais. Por exemplo, quando pintinhos são privados sensorialmente de vocalizações típicas da sua espécie (mesmo que seja de suas próprias vocalizações) o imprinting não se manifesta. Evidências como essa levamnos a deduzir que o comportamento instintivo necessita de interações, ainda que sutis, de experiências sensoriais entre os seres da mesma espécie para que o gene atue.

O vínculo de apego entre mães e filhotes de mamíferos foi originalmente estudado pelo psicólogo americano, Harry Harlow ${ }^{6}$ e aprofun- 
dado por Bowlby ${ }^{7}$ e Bowlby e Ainsworth, ${ }^{8}$ em meados do século passado, descreve seus experimentos com privação materna e isolamento social de primatas. Harlow ${ }^{6}$ demonstrou que o apego entre filhote de rhesus não era eliciado, primariamente, pela busca da satisfação alimentar, mas sim, em razão do aconchego que eles encontravam num modelo de mãe revestida de tecido. Concluiu, também, que o vínculo mãefilhote é a base de todos os outros laços afetivos e, portanto, configura-se como essencial para a saúde mental e para o desenvolvimento normal em primatas.

Concordando com Harlow e opondo-se à visão psicanalítica, o psicanalista dissidente Bowlby ${ }^{6}$ defende que os bebês, desde quase imediatamente após o seu nascimento, respondem de forma peculiar frente a certos padrões de estímulos que lhes são biologicamente interessantes. A tese que Bowlby ${ }^{7}$ defendeu diante da sociedade psicanalítica da época, composta por renomados teóricos do desenvolvimento infantil como Spitz, Winnicott, Melanie Klein, e Lebovici, foi a de que Freud estava errado ao afirmar que o apego entre mãe e bebê resultava de experiências prazerosas do bebê quando tinha temporariamente satisfeitas suas necessidades pulsionais orais. Para Freud a mãe seria investida libidinalmente por ser a figura que promovia essa satisfação oral primária. Dito de outra forma, a necessidade oral seria de primeira ordem, enquanto que a de vinculação social seria de segunda ordem, na visão psicanalítica clássica. Para Bowlby $^{8}$, as evidências empíricas de Harlow ${ }^{6}$ eram mais convincentes do que as especulações psicanalíticas. O que agora parece razoável, na época rendeu uma carta de protesto formal escrita pelos seus colegas psicanalistas ${ }^{10}$.

A teoria do apego infantil de Bowlby, como ficou conhecida, defende a tese de que, tal como os primatas inferiores, os primatas superiores nascem com predisposições biológicas para buscar proximidade com outros humanos, que não estão primeiramente ligadas à satisfação de necessidades de alimentação. A necessidade social é primária e é ela quem desencadeia o vínculo de apego. Além disso, esse comportamento, uma vez iniciado, somente poderá ser terminado pela ação de sua contraparte, o comportamento parental ${ }^{7}$.

Bowlby, nesse artigo, também questiona outras teses clássicas da psicanálise sobre a condição psíquica do recém-nascido. Para o autor, seriam plenamente refutáveis as premissas teóricas da existência de um período de autismo normal ou período simbiótico descrito por Mahler ${ }^{11}$, decorrentes do estado de incapacidade quase absoluta e indiferenciação do recém-nascido defendida por Winnicott ${ }^{12}$ e Spitz $^{9}$. Também lhe parecia refutável a defesa do papel essencial que a mãe tem em promover a diferenciação progressiva rumo aos estado de independência relativa $^{12}$ - ei-la aqui de novo! - e a capacidade tardia de o bebê estabelecer verdadeiras relações objetais de SPITZ ${ }^{9}$. Bowlby apresenta à sociedade psicanalítica da década de 50 um bebê biologicamnete capacitado de competências comunicacionais e tira da mãe a total responsabilidade pelos problemas advindos dessa interação precocemente estabelecida.

Em sua teoria, identifica e descreve os padrões comportamentais que servem como sinais poderosos que os recém-nascidos emitem para eliciar o cuidado e a proteção dos adultos. Esse comportamento, na nossa espécie, engloba um conjunto de condutas inatas, exibidas pelo bebê, em condições normais de nascimento, que inclui o chorar, seguir (primeiro visualmente, depois literalmente), o agarrar-se, o aconchegar-se e o sorrir. De acordo com Bowlby ${ }^{13}$, o bebê tem essas condutas, programadas filogeneticamente, acionadas diante de sinais estressores fisiológicos como a fome, o cansaço ou a dor, ou, ainda, psicológicos, como ser deixado só por um período prolongado ${ }^{7,14}$.

Bowlby lembra que o comportamento de cuidar dos filhotes e proteger a fêmea, em dezenas de espécies, é controlado pela percepção de um estímulo-sinal, ou gestalten, como por exemplo, estender a cauda, mudanças na coloração do bico ou manifestações sonoras. Esses sinais ativam respostas especificas não somente da mãe como de outros membros da mesma espécie ${ }^{7,3,16}$

Guerra $^{4}$, numa interessante revisão das principais características da parturição e das 
condições de nascimento de diversas espécies, também constatou que não apenas a responsividade da mãe, mas a do pai ou de adultos que colaboram nos cuidados e proteção dos fllhotes, na maioria dos mamíferos, precisa ser mantida pela continuidade da proximidade com o filhote e pelos sinais de necessidade de cuidado que exibe.

Vieira e Piovanotti ${ }^{16}$, em um estudo sobre a qualidade da presença do pai no cuidado parental entre gerbilos da Mongólia, concluem que, mesmo em roedores, a experiência anterior do pai nos cuidados parentais, promovia alterações na dinâmica do casal. Os machos mais experientes em paternidade compartilhavam mais com a fêmea os cuidados dos filhotes. Essas evidências empíricas obrigam-nos a rever as explicações clássicas das funções parentais nas sociedades dos bebês do século XXI.

\section{Apego em mamíferos na abordagem evoluci- onista}

De acordo com a teoria evolucionista, os mamíferos surgiram na terra há, aproximadamente, 300 milhões de anos, evoluindo dos répteis. As mudanças adaptativas que os diferenciam dos répteis incluem o surgimento de pêlos, de glândulas sudoríparas e um mecanismo mais sofisticado de manutenção da homeostase térmica, decorrentes das variações de temperatura do ambiente nos quais os mamíferos buscaram meios de sobrevivência ${ }^{17}$.

Mudanças subseqüentes na vida terrestre também parecem ter promovido mudanças no modo de reprodução mamífera. A gestação interna, ou úterogestação- e exterogestação ${ }^{18}$ prolonga o vínculo no pós-parto e possibilita o surgimento da afeição mútua, dada a relativa imaturidade com que os diferentes mamíferos nascem. A presença de glândulas mamárias preconiza a predisposição de uma ação instintiva de sugar por parte do filhote. O comportamento materno, por sua vez, cria uma resposta à necessidade de manter proximidade dos filhotes para a amamentação. A interação íntima entre mãe e ninhada precisa ser mantida por mecanismos recíprocos de manutenção desse vínculo afetivo diferencia- do, caso contrário a sobrevivência estaria ameaçada ${ }^{19}$.

Para Bussab ${ }^{19,20,21}$, o desenvolvimento do apego no gênero homo deve-se a fatores fundamentais relacionados às modificações adaptativas na reprodução humana, em conseqüência das transformações que a marcha bípede trouxe. O bipedismo promoveu modificações anatômicas na pélvis bastante significativas para que marcha fosse possível. Dentre as conseqüências do bipedismo estão as modificações do tempo da gestação humana. Filhotes que usufruíam de grande período de gestação encontraram maior dificuldade de sobrevivência, já que não podiam passar no canal da pélvis ${ }^{18,21,19}$. A seleção natural tratou de dar mais chances de sobrevivência aos filhotes nascidos em condições prematuras, já que poderiam transpor as barreiras anatômicas impostas pela postura bípede sem representar risco de morte materna. Nascer pequeno parece ter sido a saída que a evolução encontrou para garantir a perpetuação da espécie humana. ${ }^{19,21,22}$

De fato, o período gestacional humano parece ter um valor direto de sobrevivência para os filhotes e mãe humanos. Ao fazer um paralelo entre o período gestacional humano e o de outros animais, levando em conta o tempo que o cérebro humano precisaria permanecer no útero para nascer em condições de auto-suficiência mínima, concluiu-se que esse período deveria ser quase três vezes superior ao que de fato o é na nossa espécie. Estudiosos afirmam que esse tempo deveria ser precisamente de 21 meses $^{23}$. Isso implica dizer que nossos neonatos nascem um ano antes do que supostamente deveriam nascer, se comparados com outros filhotes de mamíferos, inclusive com os primatas.

A esse fator adaptativo deu-se o nome de neotenia. Segundo Blanc ${ }^{24}$ a neotenia é o termo empregado por biólogos etologistas para descrever este fenômeno de juvenilização, isso é, a progressiva mutação dos genes de regulação do desenvolvimento, com o efeito retardar, consideravelmente, a totalidade do desenvolvimento pré e pós-natal nos mamíferos. O desenvolvimento da neotenia permitiu o envolvimento dos adultos nos cuidados parentais e, em muitos casos, aloparen- 
tais ${ }^{4,22}$. Há evidências que as características típicas de um rosto de bebê, como o formato arredondado, olhos amendoados, testa abobadada, nariz menor, bochechas arredondadas e queixo recuado, sirvam de sinais poderosos para provocar sentimentos ternos e protetores dos adultos ${ }^{21,22}$. A neotenia, dito de outra forma, foi o meio que a natureza humana encontrou para garantir que os progenitores permanecessem próximos aos filhotes, atraídos por uma força irresistível de cuidálos e mantê-los saudáveis e seguros, sempre que solicitados. Essa interação particularizada entre mãe-filhote parece ter dado origem às primeiras interações “afetivas” entre os organismos Foi, também, essa fragilidade neonatal que permitiu aos mamíferos humanos formar laços particularizados de afeto ${ }^{21,22}$.

Da mesma forma, Eibl-Eibesfeldt ${ }^{25}$, defende que o desenvolvimento da sociabilidade dos vertebrados decorre da evolução do cuidado parental na relação pais-filhos. Esse fato criou condições para o desenvolvimento das relações amigáveis e afetivas dos adultos. No caso da espécie humana, o vínculo do apego e o desenvolvimento da instituição familiar, aparentemente, têm suas origens nessa modalidade inédita interativa entre mães e filhotes ${ }^{26}$.. Bussab ${ }^{26}$, ao explicitar as possíveis contribuições da perspectiva etológica para a compreensão do funcionamento familiar, conclui que a interação mãe e filho, bem como os modos particulares das interações familiares em humanos dependem de circunstâncias ecológica e historicamente produzidas.

Numa extensa revisão bibliográfica das evidências empíricas oferecidas pela etologia, Schön ${ }^{18}$ conclui que os cuidados parentais nas sociedades ocidentais industrializadas estão impondo conflitos importantes para o neonato. Para a autora já existe evidência suficiente de que haja efeitos benéficos na adoção de um estilo parental natural ( "Natural Parenting") que tem como base a sensibilidade e a responsividade dos pais aos sinais de apego que o bebê humano emite. Para essa autora, se a sociedade moderna apregoa que o contato físico e a proximidade não são mais necessários, e mesmo são indesejáveis, como insistem alguns documentos oficiais que recomendam "que pais devem evitar atender às demandas de proximidade de bebê por que isso poderá torna-lo uma criança mal-acostumada e mimada, além de um tirano que fará da mãe sua escrava"18, estamos colocando o bebê humano diante de um conflito para o qual não está adaptado biologicamente. Diante dessa situação inédita para a espécie, novas discussões e estudos no campo do desenvolvimento neonatal e das interações sociais precoces são oportunamente bem vindas.

\section{A gestação e o pós-parto}

O período pós-parto tem sido definido como um momento de extrema felicidade para os pais e familiares, ao mesmo tempo em que são potencialmente ansiogênicos para a família, a ponto de interferir negativamente na relação do casal e no desenvolvimento afetivo, social e cognitivo da criança.

Schwengber e Piccini ${ }^{27}$ afirmam que "o nascimento de um bebê”, principalmente se for o do primeiro filho, tem sido considerado por autores como um evento propício ao surgimento de problemas emocionais nos pais como depressões, psicoses pós-parto e manifestações psicossomáticas. Da mesma forma, Vieira e Prado $^{28}$ e Schwengber e Piccini ${ }^{27}$ afirmam que tanto as características maternas como a dos bebês podem a dificultar ou inviabilizar essa interação inicial.

Já para Silva e Botti ${ }^{29}$, o puerpério é a fase do pós-parto, na qual "os riscos de transtornos aumentam em face das preocupações, anseios e planejamentos realizados e sentidos pela puérpera”. Há, portanto, uma probabilidade de conflitos na interação mãe e filho no pós-parto, decorrentes da vivência da maternidade pela mãe, que podem variar desde a ansiedade de adequações à nova realidade situacional até distúrbios do humor como melancolia da maternidade, às psicoses puerperais.

Sotto-Mayor e Piccini ${ }^{30}$ afirmam que é muito comum ocorrer o distúrbio de labilidade transitória de humor, atingindo cerca de $60 \%$ das novas mães entre o terceiro e o quinto dia após o parto. Esse distúrbio, geralmente, desaparece de forma espontânea. Já as psicoses puerperais apresentam sintomas acentuados, e, freqüente- 
mente, precisam ser tratadas intensivamente, sendo necessária, por vezes, a internação hospitalar. Esses transtornos ocorrem entre as duas primeiras semanas após o parto, mas o número de mães acometidas é de apenas dois a quatro casos em cada mil partos. Uma outra complicação psiquiátrica bastante conhecida, que pode desencadear a psicose puerperal é a depressão pós-parto ${ }^{27,30}$.

A depressão comumente associada ao nascimento de um bebê, segundo Silva e Botti ${ }^{29}$, refere-se a um conjunto de sintomas que iniciam, geralmente, entre a quarta e oitava semanas após o parto, atingindo de 10 a 15\% das mulheres. Esses sintomas incluem irritabilidade, choro freqüente, sentimentos de desamparo e desesperança, falta de energia e motivação, desinteresse sexual, transtornos alimentares e do sono, acompanhados de sensação de incapacidade de lidar com a situação, bem como de queixas psicossomáticas $^{30}$. Segundo os autores, esses sintomas precisam ser percebidos e acompanhados pelos familiares desde o retorno da mãe com a criança ao lar, pois podem causar danos ao vínculo mãe-bebê.

Uma mãe que é impossibilitada de ficar próxima ao seu bebê, por padecer de depressão puerperal, poderia não conseguir ser responsiva às demandas do filho recém-nascido. Isso porque mães deprimidas tendem a passar menos tempo acariciando e dirigindo o olhar e a voz aos seus bebês, costumam expressar humor negativo e podem ser tornar negligentes no cumprimento das tarefas que envolvam o cuidado e a proteção do bebê. Também tendem a demonstrar menos espontaneidade ou naturalidade e menores níveis de atividade em relação ao corpo do bebê. ${ }^{27,30}$.

O distanciamento, a irritabilidade no trato e o desinteresse pelo cuidado e pela criança, de um modo geral, tendem a desencadear no bebê reações peculiares. O bebês de mães deprimidas exibem menor nível de atividade, menos propensão à socialização, costumam distanciar o olhar da face humana ou apresentam mais propensão a protestos mais intensos, mais expressões de tristeza e raiva, menos expressões de interesse e uma aparência depressiva com pou- cos meses de idade $\mathrm{e}^{27,30}$.

Tomando como base os princípios da teoria de Bowlby ${ }^{31}$ podemos inferir que a construção do vínculo de apego pode ser abalada, transitória ou definitivamente, pela indisponibilidade emocional materna. O bebê desamparado pode apresentar uma série de reações que variam de acordo com o tempo em que permanece nãoatendido. Ao que tudo indica, diante do afastamento, irritabilidade, desinteresse da mãe, haverá uma tendência de equivalente reação da criança ${ }^{27}$.

Stern $^{32}$, a partir da observação das interações face-a-face, conclui que se o bebê for submetido a sucessivos micro-eventos de depressão, ao ponto de a depressão materna se tornar familiar, o bebê poderá apresentar também sintomatologia depressiva.Para esse autor, a experiência de estar com uma mãe deprimida caracteriza-se por pelo menos quatro experiências subjetivas. A primeira ocorre quando a mãe sob depressão rompe o contato visual com o bebê e não tenta restabelecê-lo. A partir do fracasso nas suas tentativas de ter a mãe emocionalmente presente, o bebê tenta a proximidade através da identificação e da imitação. A segunda experiência subjetiva a que se refere Stern $^{32}$ é caracterizada pela experiência do bebê como um reanimador. Ela foi baseada em evidências de que o bebê, diante de uma situação de microdepressão, tenta fazer com que a mãe se restabeleça, o que muitas vezes funciona, haja vista a influência ativa do bebê no estado emocional materno. A terceira experiência subjetiva refere-se ao comportamento de desistência de investir na mãe, colocando-a em segundo plano, e a busca de outras formas de estimulação. Assim, se as tentativas de reanimar a mãe falham, o bebê parte em busca de um nível mais apropriado de estimulação e interesse no mundo. Por fim, a quarta experiência subjetiva de estar com uma mãe deprimida refere-se ao desejo do bebê estar com a mãe não-deprimida. O bebê torna-se capaz de discriminar as discrepâncias entre os momentos depressivos e não-depressivos, nos rompantes com que a mãe tenta reatar o vínculo e atender às necessidades do filho. Stern ${ }^{32}$ ressaltou que o bebê acaba aceitando o que a mãe oferece e 
quando ela está disponível, dada sua necessidade de uma interação mais viva com a mãe.

Uma outra referência importante da psicopatologia precoce é o já citado psicanalista, René Spitz. Ainda que sua visão da total incapacidade do recém-nascido tenha sido contestada pelas evidências da psicologia do desenvolvimento contemporânea, Spitz', em sua obra "O primeiro ano de vida da Criança”, descreve as modalidades de interação materno-infantil potencialmente patogênicas para o bebê, que merecem destaque neste artigo. Esse autor agrupa as patologias precoces em duas categorias: as relações inadequadas (ou de comprometimento da qualidade), que podem causar os distúrbios psicotóxicos, e as relações insuficientes (de comprometimento na quantidade), que podem causar as doenças de carência afetiva do bebê.

Dentre os distúrbios psicotóxicos, Spitz ${ }^{9}$ destaca três comportamentos maternos patogênicos. O primeiro, a rejeição primária ao recémnascido, pode ser efetuado ativa ou passivamente pela mãe. Nos casos extremos, a rejeição primária pode levar ao infanticídio. O segundo comportamento, nomeado pelo autor de superpermissividade ansiosa primária, é caracterizado por uma conduta insegura/ansiosa da mãe, ao mostrar-se excessivamente responsiva aos sinais do bebê, interpretando-os sempre como sinal de fome. A mãe pode preocupar-se com o ganho de peso, como único indicativo de saúde do bebê e cada choro ou gemido seu leva-a a colocá-lo no peito. Como resultado, a sobre-alimentação pode levar a criança a intensificar a cólica dos três meses, e aumentar as crises de choro. Em troca, ele recebe mais alimento. O movimento circular é evidente e é pertetuador da dificuldade de comunicação recíproca entre mãe e filho. Por último, dentre os distúrbios psicotóxicos, Spitz chama a atenção para as condutas maternas que oscilam entre o mimo e a hostilidade. Os bebês submetidos a esse tipo de interação podem apresentar o distúrbio de motilidade, conhecido também, como comportamento de balanço. $\mathrm{O}$ autor adverte que ainda que o comportamento seja comum em bebês, especialmente após os seis meses de idade, sua freqüência e intensidade podem torná-lo evidentemente patológico.
Ao estudar esse comportamento em instituições infantis observou em um grupo de 170 crianças a incidência e o significado de três atividades auto-eróticas no primeiro ano de vida, particularmente, o balanço, a manipulação fecal e a manipulação genital. Os pesquisadores constataram que das 170 crianças observadas, 87 apresentavam o balanço em algum período do primeiro ano de vida, enquanto 83 não apresentavam esse comportamento.

Tentou-se, a partir disso, estabelecer o que levaria certos bebês a entregarem-se ao balanço, mais particularmente, aqueles que em que era realizado com violência, envolvendo grande dispêndio de energia. Nos casos mais patológicos, o balanceio tornava-se a principal atividade do bebê, acarretando importantes atrasos na adaptação social e na capacidade de exploração manipulatória de objetos. Uma vez controladas todas as variáveis situacionais e constitucionais da criança que poderiam explicar esse comportamento, os pesquisadores chegaram à conclusão de que a relação entre as crianças que se balançavam e suas mães era bastante peculiar. Em geral, os bebês com distúrbio de motilidade tinham mães que apresentam labilidade de humor, com baixo controle das expressões emocionais. Ora os contatos com seus filhos eram permeados por expressões intensas de carinho, ora por explosões de hostilidade e fúria, sendo que essa alternância de humor variava sobremaneira ao longo do dia.

No que se refere às doenças de carência afetiva do bebê, decorrentes da privação do contato e cuidados maternos, Spitz descreve a depressão anaclítica, seguida de uma privação afetiva parcial, que pode durar de três a cinco meses, e o hospitalismo, que se revela nos casos em que o restabelecimento com um vínculo substituto não seja introduzido após cinco meses de privação afetiva. O hospitalismo decorre da privação afetiva total e tende a ser gravemente deteriorante para a saúde do bebê e, em alguns casos, irreversível.

A privação afetiva apresenta uma trajetória de evolução que pode ser observada já nos primeiros três meses de supressão dos cuidados maternos. No primeiro mês, os bebês tornam-se 
chorosos, exigentes e tendem a exibir conduta de apego com relação a qualquer pessoa que se aproxime, quando existe essa aproximação. No segundo mês seguido ao abandono, o choro sofre uma transformação expressiva, transformando-se numa espécie de gemido. Nessa fase inicia-se um processo de desaceleração do crescimento, decorrente da perda de peso do bebê ${ }^{9}$. Com o agravamento do quadro, no terceiro mês, os bebês recusam-se as tentativas de contato com humanos. Permanecem numa postura patognomônica, com pouca motilidade e tendem a ficar de bruços na cama. Os bebês passam a apresentar distúrbios de sono e inapetência, o que acelera a perda de peso. A situação nutricional aumenta os riscos de doenças infecto-contagiosas e o atraso motor torna-se generalizado. A partir daí, dá-se início a rigidez facial e marasmo, que se revela na pouca expressividade de emoções, mesmo as mais desprazerosas. Uma vez não re-estabelecida às condições de vínculo saudável com a criança, os sintomas evoluem para o quadro de hospitalismo e óbito ${ }^{9}$.

Conforme argumenta Ramires ${ }^{33}$, o modo como se estabelece o comportamento de apego em fases precoces da vida não propicia somente o surgimento de modelos internalizados de relacionamento mãe e filho, mas trazem repercussões para as relações interpessoais futuras em geral. Assim, agem primeiro sobre a dimensão cognitiva do bebê, para depois agirem sobre a sua capacidade de interagir socialmente, ou seja, na sua competência social. Entretanto, ainda que seja plenamente aceitável afirmar que a interação mãe-bebê servirá de base para as suas futuras relações, é preciso considerar seus condicionantes culturais ${ }^{28,19,34}$.Assim, parece um equívoco reducionista condenar a mãe pelas falhas de maternagem, haja vista sua natureza de múltiplas origens. Estudiosos da PDE explicam o valor de sobrevivência que um maior investimento parental, inclusive por parte do macho progenitor, adquire para algumas espécies, dentre elas, a humana ${ }^{25,35,36,37}$ De acordo com a teoria do investimento parental de Trivers, citada por Tokumaru e Bergamim ${ }^{38}$, os pais investem em seus filhos como forma de garantir melhores chances de sua reprodução e o cuidado dispendido varia- rá em função do custo envolvido, o que nos remete a questões de ordem contextuais no momento que falamos de investimento parental.

No caso do investimento materno, o retorno parece mais claramente garantido, quando o bebê nasce em condições normais. Já nas primeiras horas ele reage especificamente à voz e ao odor da mãe; com alguns meses já discrimina sua face e passa a preferi-la a qualquer outro ser humano. Embora com oito meses tendam a aparecer as reações mais típicas de apego à mãe e medo a estranhos, às vezes observa-se isso muito antes, com as crianças reagindo com medo a estranhos e mantendo a mãe como base de segurança $^{13}$.

Entretanto, com relação ao investimento parental paterno, pouco ainda se tem discuti$\mathrm{do}^{28,39,40}$. O grau de semelhança entre pai e filho tem servido como um reforço social para a iniciação e fortalecimento do vínculo pai-filho e para a promoção da estabilidade conjugal e familiar ${ }^{41}$. Entretanto, ainda que a teoria evolucionista possa predizer que homens tendam a apresentar mais apego em situações em que o grau de parentesco seja evidenciado fenotipicamente se comparado com as mulheres, e que, em particular, apresentem um maior investimento parental se crianças forem comprovadamente seus filhos biológicos, há evidências de que o fator convivência seja um forte propiciador de vinculações afetuosas entre pais e bebês, e que esse fator pode se sobrepor à natureza, por ser base da formação do apego ${ }^{19}$.

A autora aborda a importância dos cuidados paternos a partir de uma perspectiva evolucionista contemporânea, na qual a convivência e parentesco apresentam o mesmo peso: "No fundo, em condições naturais, tanto a convivência quanto o parentesco favorecem a formação de vínculos subjacentes à constituição da família ${ }^{19}$. Segundo a autora "Entre os !Kung ou entre os Eipo, a probabilidade de um bebê morrer até o segundo ano de vida é três vezes maior se ele tiver perdido o pai” (p.4)

Para os psicólogos do desenvolvimento da atualidade, os mecanismos biológicos operaram na evolução da espécie, propiciando o aumento da participação do pai nos cuidados com o recém- 
nascido. Esse incremento na qualidade da participação paterna tende a aparecer em diversos contextos culturais ${ }^{40,28}$. Wendland ${ }^{10}$, num artigo que revisa, a partir de um ponto de vista teórico e metodológico, a evolução dos estudos na área das interações pais-bebês, conclui que existe um evidente crescimento do reconhecimento da participação do pai nos cuidados parentais, haja vista a capacidade de os recém nascidos, progressivamente, partilharem a atenção para pai e para a mãe e desenvolverem-se nessa tríade interativa. Da mesma forma, Klaus, Kennel e Klaus ${ }^{42}$ defendem a imprescindibilidade de ambos (o pai e a mãe) para o desenvolvimento infantil. Outros estudiosos dos cuidados parental enfatizam a imprescindibilidade da "paternagem" na sociedade contemporânea ${ }^{40,26}$. Parece haver evidências de que a ausência ou deficiência do pai podem, inclusive, ocasionar conseqüências negativas para a mãe, mais especificamente, no modo como ela vive a gravidez e a maternidade e, portanto, ser um trigger para a depressão materna e, conseqüentemente, para o desenvolvimento mal-adaptativo do bebêe ${ }^{28}$.

Novas investigações sobre a paternidade no contexto econômico e social atual são vistas como prementes para a pesquisa do desenvolvimento infantil, no Brasil. ${ }^{40}$

\section{CONSIDERAÇÕES FINAIS}

Há um consenso em torno da idéia de que dificuldades do estabelecimento do vínculo mãebebê são sempre preocupantes sob o ponto de vista da saúde mental da mãe e do desenvolvimento do bebê e requerem intervenção especializada, especialmente se consideramos as repercussões nas futuras interações sociais da criança.

Entretanto, é possível falar que, nos casos de depressão puerperal, na qual a mãe encontra-se impossibilitada de investir nos cuidados de seu filho, outros membros da família, podem e devem suprir a maternagem, investindo na formação do vínculo de apego com o bebê, retirando-o da situação de desamparo. A participação crescente da figura paterna nos cuidados do bebê parece ser crucial para o desenvolvimento saudável do bebê e para o re-estabelecimento da saúde mental da mãe, tanto quanto para a estabilidade familiar Nesse caso, não apenas a participação do pai biológico pode ser reparadora da função materna disfuncional, mas também de pais adotivos ${ }^{38}$.

O atual momento histórico, marcado por mudanças consideráveis da estrutura e na dinâmica familiar tradicional, parece propício à revisão dos estudos sobre o cuidado parental. A saída da mulher para o mercado de trabalho, o desemprego estrutural que obriga alguns homens a permanecerem em casa, bem como a criação de creches e de outros serviços de atendimento à criança são fatores que, certamente, têm influenciado o modo como as interações familiares acontecem, já que os papéis sociais do que é ser pai, mãe e criança assumiram novas funções e vem modificando os sistemas de crenças parentais $^{34}$. Estudos que busquem compreender de que modo as variáveis sócio-culturais mediatizam as características parentais parecem fundamentais nesse campo ${ }^{34}$.

\begin{abstract}
The physical and emotional interactions established between ancestors and descendants have been reexamined in psychological science due to recent contributions offered by Evolutionary Psychology. This article reviews classic and contemporary theories of distinct philosophical backgrounds, which have tried to explain the factors implied in the genesis, development and function of the early interactions between children and their parents. A review of papers from distinct areas regarding attachment behavior and parental behavior, in its normal and pathogenic dynamics in the species homo, is presented. The psychopathology of the child's tie to the mother and its disruption through separation, deprivation and bereavement, especially puerperal depression, are analyzed, as well as the role that the paternal care assumes in this context, in order to provide the human infant with an ideal environment for optimal growth both psychologically and physiologically.
\end{abstract}

Keywords: Social interaction. Attachment. Parental behavior. 


\section{REFERÊNCIAS}

1. Darwin CR. The expression of the emotions in man and animals.1st ed. London: John Murray; 1898. Available from: URL: http://www.humannature.com/darwin/emotion/contents.

2. Lorenz KZ. Os fundamentos da Etologia. Cruz PM e Alberts CC [trad]. São Paulo: UNESP; 1995.

3. Leontiev A N. O desenvolvimento do psiquismo. Lisboa: Livros Horizonte; 1978.

4. Guerra R F. Uma análise evolucionária da parturição e desenvolvimento infantil em mamíferos. Revista de Ciências Humanas 2003; 34: 395-440.

5. Vieira M L e Prado AB. Abordagem evolucionista sobre a relação entre filogênese e ontogênese no desenvolvimento infantil. In De Moura, MLS (org.) O bebê do século XXI: e a psicologia em desenvolvimento, São Paulo: Casa do Psicólogo; 2004. p. 155-203.

6. Harlow HF. The Nature of Love University of Wisconsin, First published in American Psychologist [Serial online].1958, 13, 673-685. Available from: URL: http:// psychclassics.yorku.ca/Harlow/love.htm\#f1.

7. Bowlby J. The nature of the child's tie to his mother. International Journal of PsychoAnalysis 1958, 39, 350-373. Available from: URL: http://www.richardatkins.co.uk/atws/document/ 545.html.

8. Ainsworth MDS e Bowlby J. An Ethological Approach to Personality Development. American Psychologist.1991; 46 (4): 333-341.

9. Spitz RA . O primeiro ano de vida. 2nd ed. São Paulo: M. Fontes;1998.

10. Wendland JA. Abordagem Clínica das Interações Pais-Bebê: Perspectivas Teóricas e Metodológicas. Psicologia: Reflexão e Crítica 2001; 14(1): 45-56.

11. Mahler M. Thoughts about development and individuation. The Psychoanalytic Study of the Child 1963;18:307-324.

12. Winnicott. DW. A criança e seu mundo. $6^{\mathrm{a}}$ ed. Rio de Janeiro: Editora Zahar; 1982.

13. Bowolby J. Apego. $2^{a}$ ed. São Paulo: Martins Fontes; 1990.

14. Bowlby, J. Separação. São Paulo: Martins Fontes; 1984.

15. Luria AR Curso de psicologia geral: introdução evolucionista a psicologia. Rio de Janeiro: Civilização Brasileira, 1979. 115 p.
16. Vieira ML e Piovanotti, M I A. Relação entre a experiência parental e a presença do pai no cuidado parental em gerbilos da Mogólia (Meriones unguiculatus), Biotemas 2004 (17) 2: 149-176.

17. Darwin CR. The Descent of Man (2nd ed.) Originally published London: J. Murray 1874.

Disponível em Classics in the History of Psychology. Available from: http:// psychclassics.yorku.ca/Darwin/Descent/ index.htm.18. Schön RA. Natural Parenting: Back to Basics in Infant Care. In Evolutionary Psychology 2007, 5(1):102-183. Available from: URL: http:// www.epjournal.net.

19. Bussab VSR. A família humana vista da perspectiva etológica: natureza ou cultura? Interação 2000 (4), 9-22.

20. Bussab VSR. Uma abordagem Psicoetológica do comportamento materno. In MJR Paranhos C e VU. Cromberg (Orgs.), Comportamento materno em mamíferos. JaboticabalUniversidade Estadual Paulista: Sociedade Brasileira de Etologia. 1998. p. 17-30.

21. Bussab VSR. e Otta E.. Desenvolvimento humano: a perspectiva da etologia. Documento CRP08 1992, 2(3), 128-136.

22. Bussab VSR. e Ribeiro FJR. Biologicamente cultural. In L. Souza; M. F. Q. Freitas \& M. M. P. Rodrigues (Orgs.), Psicologia - Reflexões (im)pertinentes (p. 195-224). São Paulo: Casa do Psicólogo;1998.

23. Leakey R. A origem da espécie humana. Rio de Janeiro: Rocco, 1997.

24. Blank M. Os herdeiros de Darwin. São Paulo: Editora Pagina Aberta Ldta; 1994.

25. Eibl-Eibesfeldt, I. Human Ethology. London: Aldine de Gruyter; 1989.

26. Piccini, CA, Silva, MR; Gonçalves TR, Lopes RS e Tudge $J$. Father's involvement during the gestation. Psicol. Reflex. Crit., Porto Alegre, v. 17, n. 3, 2004. Available from: URL: http:// www.scielo.br/scielo.php.

27. Schwengber DDS e Piccini CA. O impacto da depressão pós-parto para a interação mãe-bebê. Estud. psicol. (Natal), Natal, v. 8, n. 3, 2003. Available from: URL: http://www.scielo.br/ scielo.php.

28. Prado, A B, Piovanotti, MRA, Vieira, ML. Concepções de pais e mães sobre comportamento paterno real e ideal. Psicol. estud., Maringá, 2007 (12) 1:54-64. Available from: URL: http://www.scielo.br/scielo.php.

29. Silva ETS e Botti NCL. Depressão puerperal - 
uma revisão de literatura. Revista Eletrônica de Enfermagem, v. 07, n. 02, p. 231 - 238, 2005.

Available from: URL: http://

www.revistas.ufg.br/index.php/fen.

30. Sotto-Mayor IMB e Piccini CA.

Relacionamento conjugal e depressão materna

Psicologia 2005; (36) 2:135-148.

31. Bowlby J. Uma Base Segura: aplicações

clínicas da teoria do apego. Porto Alegre: Artes Médicas; 1989.

32. Stern DN. A constelação da maternidade: 0 panorama da psicoterapia pais/bebê. Porto Alegre: Artes Médicas;1997.

33. Ramirez V R R. Cognição Social e Teoria do Apego: possíveis articulações. Psicologia: Reflexão e Crítica, 2003; 16(2): 403-410.

34. Kobarg A P R, Sachetti VAR e Viera, ML. Valores e crenças parentais: reflexões teóricas. Rev Bras Crescimento e Desenvolvimento Humano 2006; 16(2):96-102.

35. Hrdy S. Mãe natureza. Rio de Janeiro: Campus; 2001

36. Lamb M E. The role of the father in child development. 3a Ed. New York: John Wiley \& Sons; 1997.

37. Prado A B, Piovanotti M R A e Vieira, M L. Não basta ser pai, tem que participar. Psicologia
Brasil 2004; (12), 12-16.

38. Tokumaru RS e Bergamin MP. Uma abordagem evolucionista das relações pais-filhos e padrastos enteados. In A. Garcia (Ed), Relacionamento Interpessoal: Olhares Diversos. Vitória: GM Gráfica e Editora; 2005. p.29-40.

39. Ribas Adriana FP e de Seidl de Moura ML. Responsividade Materna e Teoria do Apego: Uma Discussão Crítica do Papel de Estudos Transculturais. Psicologia: Reflexão e Crítica 2004; 17(3):315-322.

40. Bandeira M, Goetz, ER, Vieira ML e Pontes, FAR. O cuidado parental e o papel do pai no contexto familiar. In Pontes, FAR, Celina, MCM, Brito, R C S, Martin, WLB (orgs). Temas pertinentes à construção da Psicologia contemporânea. Belém: Editora Universitária; 2005. p.191-230.

41. Volk AA. Parental Investment and Resemblance: Replications, Refinements and Revisions. Evolutionary Psychology, 2007; 5(1): 1-14.

42. Klaus MHK JH e Klaus P. Vínculo: construindo as bases para um apego seguro e para a independência, Porto Alegre: Artes Médicas; 2000. 